\title{
1 Estimating persistent oil contamination in tropical 2 region using vegetation indices and Random Forest 3 regression
}

4 Guillaume Lassalle $^{\mathrm{a}, \mathrm{b}}$, Anthony Credoz ${ }^{\mathrm{b}}$, Rémy Hédacq $^{\mathrm{b}}$, Georges Bertoni $^{\mathrm{c}}$, Dominique Dubucq ${ }^{\mathrm{d}}$, 5 Sophie Fabre ${ }^{\mathrm{a}}$, Arnaud Elger ${ }^{\mathrm{e}}$

6 AUTHOR ADDRESS

$7{ }^{\text {a }}$ Office National d'Études et de Recherches Aérospatiales (ONERA), Toulouse, France

$8 \quad \mathrm{~b}$ TOTAL S.A., Pôle d'Études et de Recherches de Lacq, Lacq, France

$9{ }^{\mathrm{c}}$ DynaFor, Université de Toulouse, INRA, Castanet-Tolosan, France

$10 \mathrm{~d}$ TOTAL S.A., Centre Scientifique et Technique Jean-Féger, Pau, France

$11{ }^{\mathrm{e}}$ EcoLab, Université de Toulouse, CNRS, INPT, UPS, Toulouse, France

$12 *$ *orresponding author: Guillaume Lassalle, Office National d'Études et de Recherches

13 Aérospatiales, 2 Avenue Edouard Belin, 31055 Toulouse, France; E-mail:

14 guillaume.lassalle@onera.fr

15 Keywords: reflectance spectroscopy, soil contamination, Total Petroleum Hydrocarbons, 16 vegetation indices, Random Forest 
19 The persistence of soil contamination after cessation of oil activities remains a major environmental issue in tropical regions. The assessment of the contamination is particularly difficult on vegetated sites, but promising advances in reflectance spectroscopy have recently emerged for this purpose. This study aimed to exploit vegetation reflectance for estimating low concentrations of Total Petroleum Hydrocarbons (TPH) in soils. A greenhouse experiment was carried out for 42 days on Cenchrus alopecuroides (L.) under realistic tropical conditions. The species was grown on oil-contaminated mud pit soils from industrial sites, with various concentrations of TPH. After 42 days, a significant decrease in plant growth and leaf chlorophyll and carotenoid contents was observed for plants exposed to 5 to $19 \mathrm{~g} \cdot \mathrm{kg}^{-1} \mathrm{TPH}$ in comparison to the controls $(\mathrm{p}<0.05)$. Conversely, pigment contents were higher for plants exposed to $1 \mathrm{~g}^{\mathrm{kg}} \mathrm{kg}^{-1}$ TPH (hormesis phenomenon). These modifications proportionally affected the reflectance of C. alopecuroides at leaf and plant scales, especially in the visible region around 550 and $700 \mathrm{~nm} .33$ vegetation indices were used for linking the biochemical and spectral responses of the species to oil using elastic net regressions. The established models indicated that chlorophylls a and $\mathrm{b}$ and $\beta$-carotene were the main pigments involved in the modifications of reflectance $\left(\mathrm{R}^{2}>0.7\right)$. The same indices also succeeded in estimating the concentrations of TPH using random forest regression, at leaf and plant scales $\left(\mathrm{RMSE}=1.46\right.$ and $1.63 \mathrm{~g}_{\mathrm{kg}} \mathrm{kg}^{-1}$ and $\mathrm{RPD}=5.09$ and 4.44, respectively). Four out of the 33 indices contributed the most to the models $(>75 \%)$. This study opens up encouraging perspectives for monitoring the cessation of oil activities in tropical regions. Further researches will focus on the application of our approach at larger scale, on airborne and satellite imagery.

1. Introduction

Along with its development during the last century, oil and gas industry has become a major 42 source of contamination in the environment (Barraza et al., 2018; Durango-Cordero et al., 2018; 43 Ogri, 2001; Romero et al., 2017). Crude oil and by-products (e.g. petroleum products, 44 wastewater, oil sludge) are frequently released in soils, following accidental facility failures, bad 45 practices and, more rarely, storm events (Ahmadun et al., 2009; Chang and Lin, 2006; Correa 46 Pabón et al., 2019; Hu et al., 2013). They cause important ecological disturbances, because oil 
contaminants - especially Total Petroleum Hydrocarbons (TPH) - are highly toxic toward 48 organisms (Bejarano and Michel, 2016; Finer et al., 2008; Merkl et al., 2004). The contamination of soil may persist in brownfields and mud pits after cessation of the oil production activity and affect ecosystems on the long term (Lassalle et al., 2019b, 2019a). The monitoring of oil activities has therefore become a critical environmental issue, and gave rise to an increasing need in reliable and cost-effective methods for assessing soil contamination. For this purpose, reflectance spectroscopy provided promising results when applied to bare soils (Correa Pabón and de Souza Filho, 2016; Scafutto and de Souza Filho, 2016). Its application to multi- and hyperspectral remote sensing imagery makes possible to detect and quantify soil TPH content at large scale using airborne sensors (Correa Pabón et al., 2019; Scafutto et al., 2017). More recently, a new approach has been proposed to extend its use to vegetated areas, where oil cannot be detected directly at the soil surface (Lassalle et al., 2018; Rosso et al., 2005; Sanches et al., 2013a). This approach shows great interest in tropical regions, where vegetation is particularly dense (Achard et al., 2018; Adamu et al., 2018; Arellano et al., 2015).

TPH affect vegetation health - especially pigment and water contents - and optical properties in the reflective domain ( $400-2500 \mathrm{~nm}$ ) (Balliana et al., 2017; Emengini et al., 2013a; Rosso et al., 2005; Tran et al., 2018). By exploiting the reflectance of leaves and canopies at particular wavelengths, it is possible to detect the changes induced by TPH in leaf biochemistry (Gürtler et al., 2018; Lassalle et al., 2018; Sanches et al., 2013a). This approach is however still under development and needs further improvements in order to be used operationally. Methods based on vegetation indices (VI) (i.e. reflectance ratios) have succeeded in distinguishing healthy and oil-exposed vegetation and in discriminating among various types of oil contamination, under controlled and natural conditions (Emengini et al., 2013a; Lassalle et al., 2019b). In recent studies, TPH were accurately detected from satellite images (Arellano et al., 2015), but their quantification remains rarely considered, although it is of great interest for assessing the

72 environmental risks deriving from the contamination.

73 The quantification of TPH remains a major challenge, as it implies tracking little variations in 74 leaf biochemistry from its reflectance. This might be particularly difficult on contaminated 75 brownfields and mud pits, because the established species are particularly tolerant to oil exposure 76 (Credoz et al., 2016; Lassalle et al., 2019b). This difficulty is moreover enhanced when dealing with low TPH concentrations, for two main reasons. In most cases, the lower the concentration, 
the lower the effects on vegetation health and reflectance (Emengini et al., 2013a; Sanches et al.,

79 2013a). These effects become more difficult to detect below a certain concentration (Lassalle et

80 al., 2019b). Moreover, some species undergo a stimulation of growth under exposure to low oil

81 contamination (Kirk et al., 2002; Lin et al., 2002). It is particularly frequent for tropical species.

82 These phenomena make the quantification of TPH very challenging using vegetation reflectance.

83 Previous studies focusing on heavy metals - which is a very different context of soil

84 contamination - achieved accurate quantification of these compounds by exploiting reflectance

85 data in empirical univariate regression models and in Partial Least Square Regression (PLSR)

86 (Shi et al., 2014b, 2014a). Similar approaches proved efficient for quantifying high levels of

87 TPH contamination (up to $77 \mathrm{~g} . \mathrm{kg}^{-1}$ ) in our previous study (Lassalle et al., 2019a), but became

88 ineffective below a certain concentration $\left(\sim 20 \mathrm{~g} \cdot \mathrm{kg}^{-1}\right)$. So, to date, there is still no evidence that

89 low levels of TPH can be quantified using vegetation reflectance, especially in tropical region.

90 To achieve this, alternative methods are necessary. Emerging machine learning methods, which

91 proved efficient for solving complex regression problems, could help quantifying low TPH

92 concentrations (Hastie et al., 2017; Breiman, 2001).

93 This study aims to assess the potential and limits of vegetation reflectance for quantifying low

94 TPH concentrations in soils, under controlled conditions. The proposed approach relies on the 95 combination of VI and a machine learning method - namely Random Forest (RF) regression.

96 This method was tested on reflectance measurements performed at various acquisition scales, 97 under realistic tropical conditions.

2. Materials and Methods

\subsection{Study site and greenhouse experiment}

An experiment was carried out for 42 days, for which a realistic case of oil contamination was reproduced under controlled tropical conditions. An industrial vegetated mud pit located in tropical region was identified for this purpose. Residues of oil production have been accumulated on this site resulted in persistent oil contamination in soils. After cessation of the activity, the site has been colonized by herbaceous vegetation, mainly Cenchrus alopecuroides (L.). The experiment focused on this species, which proved good indicator of oil contamination in 107 previous studies (Emengini et al., 2013c; Lassalle et al., 2018). To reproduce as faithfully as 
possible the conditions of the mud pit, the soil was sampled on two locations of the site and used in the experiment. Soil analyses revealed low concentrations of BTEX and Polycyclic Aromatic Hydrocarbons (PAHs) in both samples, and $\mathrm{C}_{5}-\mathrm{C}_{40} \mathrm{TPH}$ concentrations of 5 and $21 \mathrm{~g}^{-\mathrm{kg}^{-1}}$, respectively. The lower $\left(\mathrm{C}_{5}-\mathrm{C}_{10}\right)$ and intermediate $\left(\mathrm{C}_{10}-\mathrm{C}_{21}\right)$ hydrocarbon fractions have been partially degraded, so the remaining contamination mostly came from the dense ones $\left(\mathrm{C}_{21}-\mathrm{C}_{40}\right.$ hydrocarbons), which are poorly degradable and whose uptake by roots is very limited (Lassalle et al., 2019b). Detailed soil analyses can be found in the Supporting Information section. No substantial change in TPH concentrations was observed for the different treatments at the end of the experiment (data not shown). In addition, an uncontaminated soil with similar texture was sampled on another site and used in the experiment. All the soils were homogenized manually and sieved to $10 \mathrm{~mm}$ to remove coarse root residuals.

Five treatments were applied to C. alopecuroides for the greenhouse experiment, with TPH concentrations ranging from 0 to $19 \mathrm{~g} . \mathrm{kg}^{-1}$. For this purpose, the soils sampled on the mud pit and the control site were mixed in varying proportions to obtain five levels of contamination, respectively 0 (control), 1, 5, 13 and 19 g. $\mathrm{kg}^{-1} \mathrm{TPH}$ (see Supporting Information). Cultivated young plants were acclimated for 15 days in greenhouse and reached $15-\mathrm{cm}$ height before being transplanted in individual pots filled with a $3-\mathrm{cm}$ layer of clay balls and $3 \mathrm{~L}$ of the corresponding treatment soil. For each treatment, 11 replicates were grown for 42 days in May and June at $27^{\circ}$ $\mathrm{C}$ and 70\% hygrometry, with a 12:12 light:dark photoperiod provided by natural and artificial light. N-P-K (6-6-6) fertilization was applied weekly to the plants, which were irrigated to field capacity every day. At the end of the experiment, plant shoots were harvested, oven-dried for 48 $\mathrm{h}$ at $60^{\circ} \mathrm{C}$ and then weighed.

\subsection{Biochemical analyses and reflectance acquisitions}

The biochemical and spectral responses of $C$. alopecuroides to the treatments were measured during the study. For this purpose, we followed the procedure described in Lassalle et al. (2019b). Young leaves were sampled on five different replicates per treatment and served for determining leaf water (LWC) and pigment contents (Arellano et al., 2015; Diepens et al., 2017). Leaf pigment content was quantified by High Pressure Liquid Chromatography (HPLC), and included chlorophylls $\mathrm{a}$ and $\mathrm{b}$ and various carotenoids, such as $\beta$-carotene, lutein, antheraxanthin, violaxanthin and zeaxanthin (Barlow et al., 1996). Differences among the treatments were 
analyzed through ANOVA and Tukey post-hoc tests. In addition, the spectral reflectance of the

140 same sampled leaves was measured following the protocol described below, and linked to

141 biochemical analyses (see section 2.3). This procedure was carried out after 21 and 42 day of

142 experiment. No leaf was sampled before in order to avoid influencing plant growth during early 143 stages.

144 Reflectance measurements were also performed directly on the plants (i.e. without picking 145 leaves) at day 0, 21 and 42, using an ASD FieldSpec 4 Hi-Res spectroradiometer (Malvern 146 Panalytical, Malvern, UK). Data were acquired in radiance in the reflective domain (400 - 2400 $147 \mathrm{~nm}$ ) and converted to reflectance using a white reference calibration panel (Spectralon, 148 Labsphere Inc., North Sutton, USA) (Milton, 1987). For each treatment, three leaves per 149 replicate were measured at random $(n=165$ spectra per date) using a leaf-clip with an internal 150 light source (10 measurements averaged per leaf). Additional measurements were conducted at 151 plant scale, by placing a $10^{\circ}$-FOV fore-optic above the pots to obtain a 5 -cm wide acquisition 152 footprint (10 measurements averaged per plant). These measurements were performed on each 153 replicate ( $\mathrm{n}=55$ spectra per date) under natural light between 11.30 am and $1.30 \mathrm{pm}$, under clear 154 sky. The reflectance data from the $1350-1450$ and $1800-1950 \mathrm{~nm}$ ranges were not conserved, 155 because of low atmospheric transmission at plant scale. A Savitzky-Golay smoothing filter was 156 then applied at the remaining wavelengths, improving the signal-to-noise ratio (Savitzky and 157 Golay, 1964).

\subsection{Vegetation indices}

160 In this study, 33 VI were computed and used in two ways. They are listed in the Supporting 161 Information section. These indices have been specifically exploited for detecting oil-induced 162 changes in leaf biochemistry in our previous study, so here they were tested for quantifying TPH 163 (Lassalle et al. 2019b). Most of them exploited reflectance in the visible (VIS) region (450 - 700 $164 \mathrm{~nm}$ ), which is the most important spectrum region for assessing oil contamination. It has been 165 shown that under exposure to oil, changes in the values of a single vegetation index result from 166 the alteration of several inter-correlated pigments that share common light absorption features 167 (e.g. chlorophylls and carotenoids). Consequently, the pigments to which an index has been 168 initially linked in the literature may differ from those involved in the response to oil exposure. 169 So, it is necessary to identify which pigments contribute the most to index changes, in order to 
170 understand how vegetation reflectance is affected by oil. For this purpose, the 33 indices were 171 first computed from the reflectance data of leaves sampled for biochemical analyses, and each of 172 them was linked to leaf pigment and water contents using Elastic net (ENET) multiple regression 173 (Zou and Hastie, 2005), as described in Lassalle et al. (2019b). ENET is a penalized least 174 squared regression method that allows selecting predictors under multicollinearity. 175 Multicollinearity appears when predictors - in our case, leaf pigment contents - are linear 176 combination of each other, and results in confusions when selecting those contributing the most 177 to the target variable (i.e. VI) (Belsley et al., 1980; Dormann et al., 2013). ENET regression 178 prevents from such consequences and has already proved efficient for identifying biochemical 179 parameters involved in reflectance changes under exposure to contaminants (Lassalle et al., 180 2019b). For each VI, the best predictors were retained and the $\mathrm{R}^{2}$ of the model was calculated.

181 In a second time, the same 33 indices were computed from the reflectance data acquired at leaf 182 and plant scales and used for predicting TPH concentrations using RF regression (Breiman, 183 2001). RF is an ensemble method that builds and average a lot of independent decision trees to 184 model the relationship between predictors (i.e. the $33 \mathrm{VI}$ ) and a response variable - here, TPH 185 concentration (Hastie et al., 2017; Hutengs and Vohland, 2016; Mutanga et al., 2012). Each tree 186 is constructed from a set of decision rules that results from the recursive fragmentation of the 187 original space into successively smaller sub-regions. To define these sub-regions, binary splits 188 are applied independently to each vegetation index. A simple model is then adjusted between VI 189 and TPH concentrations with respect to the splits, and those minimizing the mean squared error 190 between the measured and predicted concentrations are retained. The succession of the selected 191 index splits represents the branches of the decision tree, in such a way that each set of decision 192 rules leads to an estimation of TPH concentration (see Hutengs \& Vohland (2016) for a complete 193 description). RF accounts for non-linear relationships between the predictors and the response 194 variable - which can occur for low concentrations of contaminants, so it was of great interest in 195 our case. Moreover, RF informs on the relative contribution of VI to the quantification of TPH 196 (Breiman, 2001; Grömping, 2009), which is essential for operational applications of the method. 197 The RF regression was fitted to half of the data (50\% training set) and tested on the remaining 198 part (50\% test set), at leaf and plant scales separately (Lassalle et al., 2019b, 2019a). For this 199 purpose, we used the data from day 42, because no difference among the treatments was 200 observed on the previous dates, so no quantification of TPH was possible (see section 3.1). The 
201 predictions of TPH made on the test set were compared to those from initial soil analyses based 202 on the $\mathrm{R}^{2}$, the Root Mean Squared Error (RMSE) and the Residual Predictive Deviation (RPD)

203 (Shi et al., 2014). The RPD denotes the ratio of the standard deviation of the measured TPH 204 concentrations to the RMSE calculated between the measured and predicted concentrations.

3. Results and discussion

\subsection{Biochemical and spectral responses to oil contamination}

As expected, C. alopecuroides was highly tolerant to oil, as none of the plants from the contaminated treatments died during the experiment. This observation is consistent with previous studies carried out on the same species with various types of oil contamination (engine oil and oil and gas waste mud) (Emengini et al., 2013c; Lassalle et al., 2018). No visible stress symptom was observed on any of the replicates before the last stages of the experiment ( $35-42$ days), so no difference in leaf pigment contents and in leaf and plant reflectance was observed among the treatments on the previous dates ( 0 and 21 days, data not shown). On day 42, leaf discoloration was observed for the individuals exposed to 5 g. $\mathrm{kg}^{-1}$ TPH or more, expressing a significant decrease in leaf chlorophyll and carotenoid contents when compared to the control $(p<0.05)$ (Fig. 1). Plant growth was also significantly affected on this date. The alterations in pigment contents induced an increase of reflectance by 5 to $10 \%$ in the VIS region, especially around 550 and $700 \mathrm{~nm}$ (Fig. 2). Other regions of the spectrum were also affected in the same way by

221 also influenced by plant architecture, background soil and illuminating and viewing geometry 222 (Asner, 1997; Sanches et al., 2013a). As suggested in previous works (Emengini et al., 2013c; 223 Lassalle et al., 2018), the late response of C. alopecuroides to oil highlights its interest for 224 monitoring long-term contaminated sites, especially brownfields and mud pits remaining after 225 cessation of oil and gas activities. 

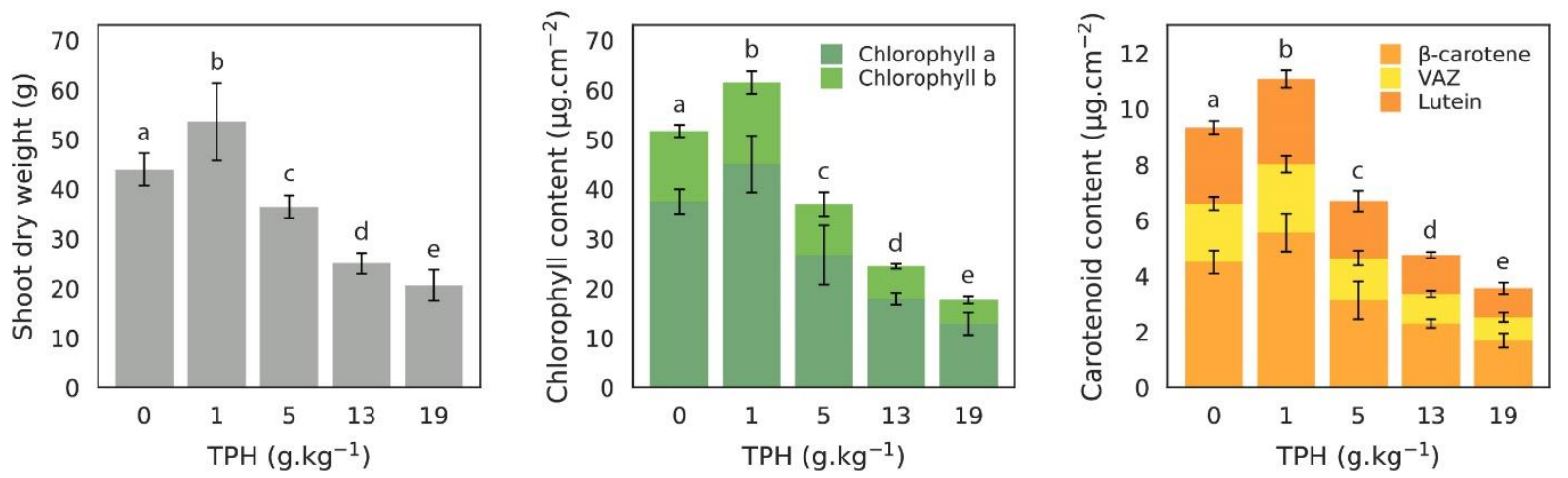

Figure 1. Shoot dry weight and leaf chlorophyll and carotenoid contents (mean $\pm \mathrm{SD} ; \mathrm{n}=11$ and

2295 samples per treatment, respectively) of $C$. alopecuroides after 42 days of exposure to various levels of Total Petroleum Hydrocarbons (TPH). Significant differences among the treatments are denoted by different lowercase letters (ANOVA and Tukey post-hoc tests, $\mathrm{p}<0.05$ ). (VAZ:

Violaxanthin + Antheraxanthin + Zeaxanthin.) exposed to contaminants (Balliana et al., 2017; Lassalle et al., 2019b; Rosso et al., 2005; Sanches et al., 2013a). They depend on multiple factors, especially the species, the contamination type and concentration and the time of exposure, and have been previously observed on $C$. alopecuroides and other tropical species (Arellano et al., 2017b; Emengini et al., 2013c; Lassalle et al., 2017). In the case of oil, these alterations result from the reduction of water and nutrient availability in soils and uptake capacities of roots (Athar et al., 2016; Balasubramaniyam and Harvey, 2014; Nie et al., 2011). Additional effects may come from the accumulation of

243 are unlikely to explain the responses observed in our experiment. The amplitude of these

244 biochemical and spectral responses was determined by the level of contamination, which 245 confirmed previous results obtained for higher levels of oil (Emengini et al., 2013c; Sanches et 246 al., 2013a). The more the TPH, the lower the leaf pigment contents and the higher the reflectance

247 (Fig. 2). Consequently, leaf chlorophyll content felt to $17.7( \pm 3.0) \mu \mathrm{g} . \mathrm{cm}^{-2}$ under exposure to 19 248 g.kg ${ }^{-1} \mathrm{TPH}$, while it reached $51.7( \pm 3.5) \mu \mathrm{g} . \mathrm{cm}^{-2}$ for control at the end of the experiment (Fig.

249 1). A similar trend was observed on carotenoids, and suggested being able to discriminate among 250 the different levels of contamination using reflectance data. 

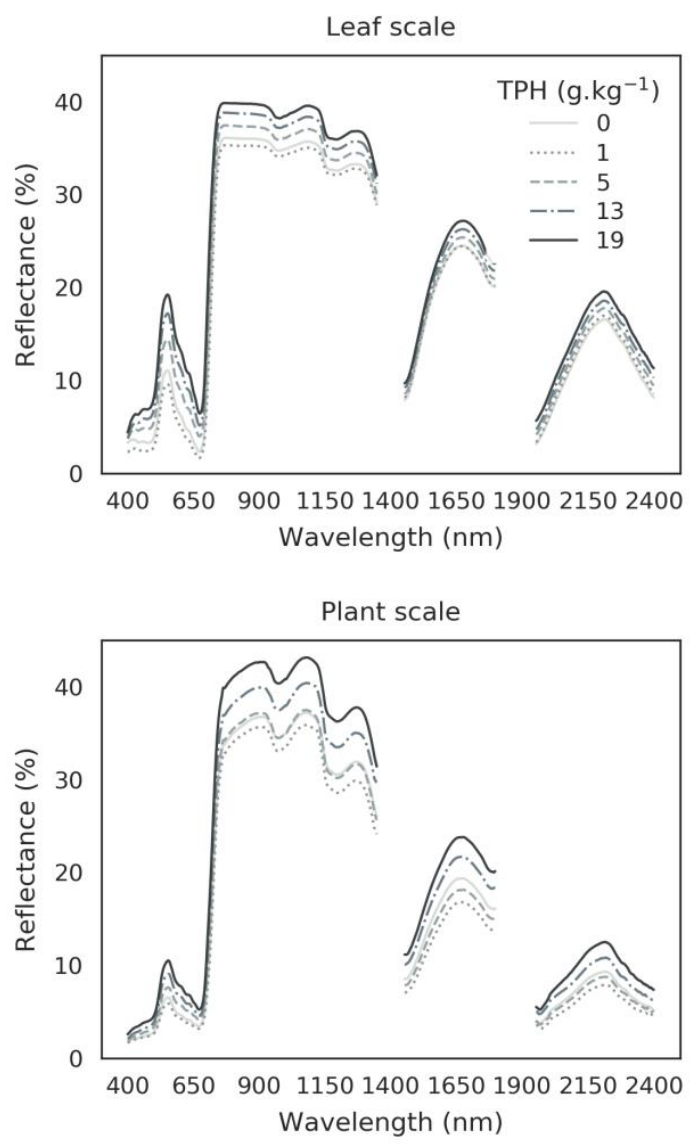

Figure 2. Mean reflectance of C. alopecuroides in the reflective domain after 42 days of exposure to various levels of Total Petroleum Hydrocarbons (TPH), at leaf and plant scales.

255 Reflectance data from the 1350-1450 and 1800-1950 intervals were removed, because of low atmospheric transmission at plant scale. (The legend is common to both figures.)

258 In contrast to the other treatments, a stimulating effect was observed for plants exposed to 1 259 g.kg ${ }^{-1}$ TPH. Shoot dry weight and leaf chlorophyll and carotenoid contents were significantly 260 higher for this treatment than those of the control $(\mathrm{p}<0.05)$, and reflectance was slightly lower 261 at leaf and plant scales. This particular response - called hormesis - has already been observed 262 on the growth of other oil-exposed species in previous studies (Kirk et al., 2002; Lin et al., 2002; 263 Salanitro et al., 1997). However, its causes remain poorly documented. To our knowledge, this 264 study is the first to bring evidence of this phenomenon using reflectance measurements. Previous 265 experiments aimed to simulate accidental oil spills (e.g. pipeline leakage), by applying high 
266 doses of oil - mainly diesel or engine oil - to crop species, which are particularly sensitive to 267 such contamination (Emengini et al., 2013a; Gürtler et al., 2018; Sanches et al., 2013a). 268 Consequently, strong alterations in leaf biochemistry and reflectance have been observed 269 regardless of the contamination level, so no hormesis has been noticed. The responses of $C$. 270 alopecuroides observed in our study substantially differed, because we focused on a totally 271 different context. When oil contamination persists in industrial brownfield and mud pit soils 272 such as that reproduced in our experiment, the most phytotoxic fractions of petroleum 273 hydrocarbons (e.g. BTEX, PAH) are almost absent from the mixture. The effects on oil-tolerant 274 established vegetation are therefore much less pronounced than those observed for other types of 275 oil contamination with high proportion of these compounds (e.g. crude oil, diesel, gasoline), 276 especially at low concentration (Lassalle et al., 2019b). Here, PAHs and BTEX were found 277 below the detection limits ( 0.02 and $0.05 \mathrm{mg} \cdot \mathrm{kg}^{-1}$, respectively) at $1 \mathrm{~g}^{\mathrm{kg}} \mathrm{kg}^{-1}$ of TPH and in the 278 control soil, so they did not affect the plants negatively. Conversely, these compounds are likely 279 to induce positive effects at very low concentration (Maliszewska-Kordybach and Smreczak, 280 2000), but they cannot be the only contaminants responsible for the differences observed

281 between the two treatments. Some other hydrocarbon fractions - which were absent from the 282 control soil - enhance the availability of nutrients and organic matter for plants by stimulating 283 microorganisms ( $\mathrm{Li}$ et al., 1990). Therefore, the very low concentrations of PAHs and BTEX 284 combined to those of other hydrocarbon fractions might have induced the hormetic effect 285 observed in this study.

3.2. Vegetation indices

\subsubsection{Elastic net regressions}

The VI succeeded in linking the biochemical and spectral responses of C. alopecuroides to oil contamination. 20 out of the 33 indices tested were strongly correlated to leaf pigment or water content $\left(\mathrm{R}^{2} \geq 0.7\right)$ (Tab. 1). For most of them, at least three contributing pigments were identified, the others having not being retained by the ENET regression. Chlorophylls and $\beta$ carotene were often the most contributing ones, and provided some of the best models $\left(R^{2} \geq 0.8\right)$ when used together (i.e. without addition of other carotenoids). Therefore, these pigments explained most of the modifications in reflectance observed among the treatments in the VIS 
296 region. Other carotenoid pigments - especially lutein and violaxanthin - were frequently retained 297 in the models (e.g. GM2 and PSSRb indices), thus confirming previous results obtained on 298 another oil-tolerant species (Lassalle et al., 2019b). These pigment are usually of less 299 contribution to leaf optical properties, because of the masking effect of chlorophylls, which are 300 present at higher concentrations in leaves and share common light absorption features (Feret et 301 al., 2008; Zhang et al., 2017). Our study shows that they also contribute to the spectral response 302 of vegetation to oil contamination.

303 
Table 1. Results of the elastic net regressions performed on the 33 vegetation indices. For each index, the $\mathrm{R}^{2}$ of the model is presented, along with the contributing set of biochemical parameters (in order of importance). (Chl a: Chlorophyll a, Chl b: Chlorophyll b, B-car: $\beta$ 307 carotene, Lut: Lutein, Ant: Antheraxanthin, Vio: Violaxanthin, Zea: Zeaxanthin, LWC: Leaf

Water Content.)

\begin{tabular}{ccc} 
Index & $\mathrm{R}^{2}$ & Pigments \\
\hline CARI & 0.76 & B-car, Chl b \\
CCI & 0.73 & B-car, Chl b, Chl a \\
CTR1 & 0.24 & Vio, B-car, Chl b, Lut, Ant, Zea, Chl a \\
CTR2 & 0.81 & Chl a, Chl b \\
GM1 & 0.84 & B-car, Chl b, Chl a \\
GM2 & 0.87 & Chl a, Chl b, B-car, Lut \\
LI1 & 0.65 & Chl a, Chl b \\
LI2 & 0.18 & Chl a \\
LI3 & 0.42 & Vio, Lut, Ant, Zea, B-car, Chl b, Chl a \\
mCARI1 & 0.43 & Ant, B-car, Lut, Chl b, Zea, Chl a \\
mCARI2 & 0.12 & Chl a \\
mSR705 & 0.72 & Chl a \\
MTCI & 0.84 & Chl a, Chl b \\
ND705 & 0.82 & B-car, Chl b, Chl a \\
PRI1 & 0.54 & B-car, Vio, Chl b, Zea, Ant, Chl a, Lut \\
PRI2 & 0.67 & Chl b, Chl a \\
PRI3 & 0.63 & Chl b, Chl a, Lut \\
PSRI & 0.43 & B-car, Chl b, Lut, Ant, Zea, Chl a \\
PSSRa & 0.72 & Chl a \\
PSSRb & 0.88 & Chl a, Chl b, Lut, B-car, Vio \\
PSSRc & 0.83 & Chl a \\
SIPI1 & 0.71 & Chl a, Chl b \\
SIPI2 & 0.81 & Chl a, Chl b \\
SIPI3 & 0.73 & Chl a, Chl b \\
SR705 & 0.83 & B-car, Chl b, Chl a \\
TCARI & 0.68 & B-car, Chl b, Chl a \\
TCARI_OSAVI & 0.75 & B-car, Chl b, Chl a \\
VOG1 & 0.75 & B-car, Chl b, Chl a \\
VOG2 & 0.7 & B-car, Chl b, Chl a \\
VOG3 & 0.71 & B-car, Chl b, Vio, Chl a \\
DWSI & 0.82 & LWC \\
& &
\end{tabular}

311 The close relationship between some indices and contributing pigments are illustrated in 312 Figure 3. As observed, these indices exhibited strong link with single pigment content. ENET 313 regression allowed identifying those contributing the most to index changes, in order of 
314 importance. These results confirmed the interest of combining pigment contents into multiple 315 models for better understanding the effects induced by oil contamination on vegetation 316 reflectance (Lassalle et al., 2019b). Most of the indices exploited reflectance around 550 and 700 317 nm, which was particularly affected by oil (Fig. 2), so they were particularly adapted to our 318 context of study. The same wavelengths also proved efficient for assessing soil contaminated by 319 oil and by-products in other situations (oil extraction, pipeline leakages, etc.). Zhu et al. (2014) 320 exploited reflectance at $700 \mathrm{~nm}$ for distinguishing among various levels of alteration in pigment 321 contents induced by phenanthrene contamination on Suaeda salsa. Likewise, Sanches et al. 322 (Sanches et al., 2013b) used the same spectrum region for assessing the effects of oil leakages on 323 crops species. One of the main advantages of VI relies on their robustness. Some of them remain 324 only little affected by bare soil and plant architecture, so they can be applied for tracking subtle 325 alterations in leaf pigment contents induced by oil at different acquisition scales (e.g. leaf, plant 326 and canopy) (Blackburn, 1998; Dash and Curran, 2007). For example, the same 33 indices 327 succeeded in discriminating among various types of oil contamination from leaf to canopy scales 328 in previous study (Lassalle et al., 2019b). Here, they were suitable for estimating TPH 329 concentrations in soils.
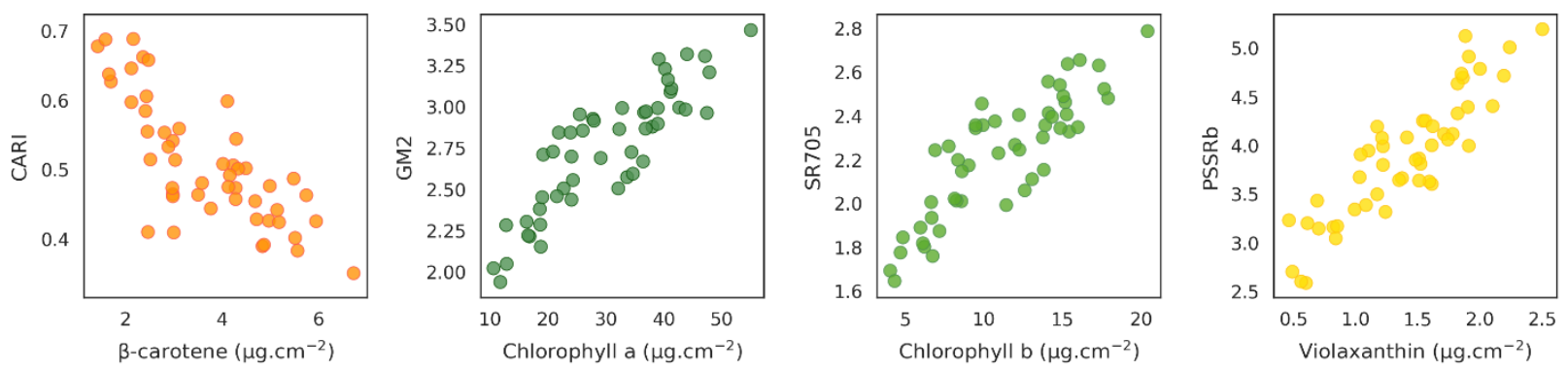

Figure 3. Relationship between vegetation indices and leaf pigment contents. Figures include data from leaves sampled on all the treatments, after 21 and 42 days of experiment $(\mathrm{n}=50)$.

RF regressions performed using the 33 VI provided accurate predictions of TPH concentrations on the test set, at leaf and plant scales. These results are presented in Figure 4. High $\mathrm{R}^{2}$ values - respectively 0.96 and 0.95 at leaf and plant scales - indicated strong correlation between the measured and predicted concentrations on the test sets. Predictions of TPH were 
very close to the true concentrations, as indicated by the low RMSE values obtained at both scales. This accuracy was confirmed by RPD values greater than 4.4. RPD provides a better interpretation of predictions, because it compares the RMSE to the variability in the true TPH 343 concentrations. RPD values above 2 or 3 are usually needed for considering the models reliable 344 for use. The 33-VI based RF models were therefore particularly adapted for estimating TPH in 345 our study. The analysis of residuals revealed that the highest level of contamination $\left(19 \mathrm{~g} \cdot \mathrm{kg}^{-1}\right)$ 346 was the most difficult to predict, as it was almost systematically underestimated (Fig. 4). This 347 may be caused by saturation in the spectral response of $C$. alopecuroides to this type of oil 348 contamination, as described for other species in previous study. Confusions also arose at the 349 lowest concentrations $\left(0-1 \mathrm{~g} \cdot \mathrm{kg}^{-1}\right)$. They highlighted the difficulty to detect the hormesis 350 phenomenon using reflectance data, for which only little differences were observed among the 351 two treatments (Fig. 2). These results thus helped identifying the detection limit of our approach.
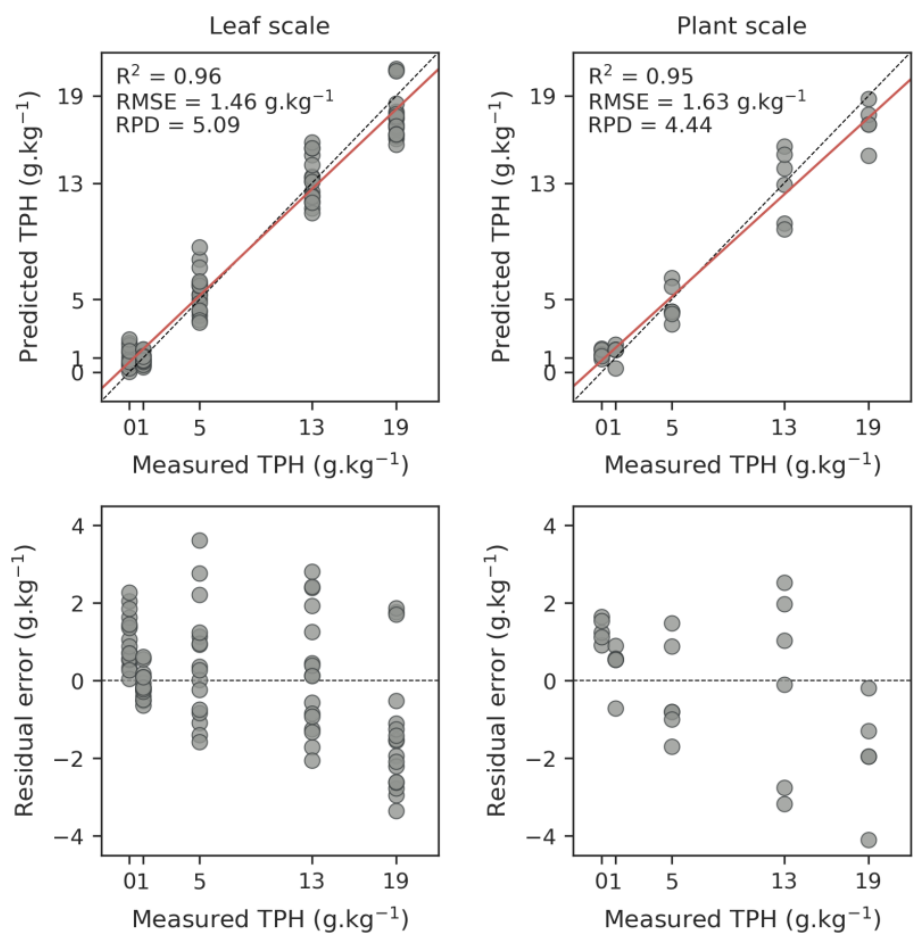

Figure 4. Comparison between the measured and predicted concentrations of Total Petroleum Hydrocarbons (TPH) using the 33 vegetation indices and the random forest regression on the test set, at leaf and plant scales (top figures), and residuals of the predictions (bottom figures). 
The relative contribution of VI to the RF models was consistent from leaf to plant scales. Four out of the 33 indices contributed the most to TPH predictions $(>75 \%$, Fig. 5). These indices were among those closely linked to leaf pigment contents $\left(\mathrm{R}^{2}>0.7\right.$, Tab. 1$)$, and more precisely chlorophylls and $\beta$-carotene. They exploit reflectance around 550 and $700 \mathrm{~nm}$, but also $670-$ 680 and $750 \mathrm{~nm}$, which helped enhancing the differences among the treatments. Only few wavelengths are therefore necessary for estimating TPH accurately using reflectance spectroscopy. Conversely, the other indices remained of little contribution to the models $(<5 \%$ each), especially those linked to additional carotenoids (e.g. lutein, violaxanthin), because they brought redundant information.

The consistence of the results between acquisition scales opens up promising perspectives for operational applications of our approach under natural conditions. Some of the main indices especially the MTCI and TCARI / OSAVI - have been originally designed for imagery application purposes (Dash and Curran, 2007; Haboudane et al., 2002), and proved efficient for detecting - but not for quantifying - oil contamination in tropical regions. For example, Arellano et al. (2015) used the MTCI index to discriminate among control and oil-contaminated sites in the Amazon forest using hyperspectral satellite images. However, the application of these indices for estimating the level of contamination remained unexplored until now. This study was a first attempt in that direction, but further researches are needed to assess the reliability of our approach under natural conditions, using field measurements, and in the long term using multiand hyperspectral imagery. High to very high spatial resolution might help achieving this, 378 because the contamination can occur on a few square meters and be therefore difficult to detect using medium to low spatial resolution imagery (Adamu et al., 2018; Arellano et al., 2015). As discussed in section 3.1, the case of persistent low contamination in brownfields and mud pits makes the estimation of TPH very challenging, because of the composition of the contamination and the tolerance of the species. Under natural conditions, additional difficulties should be considered before application of our approach. Vegetation established on brownfields and mud pits is exposed to a multitude of environmental factors that affect its health and reflectance (e.g. drought, waterlogging), especially in the tropical regions with marked seasonality (Adamu et al., 2016; Smith et al., 2004). These factors might overlap with the effects induced by TPH, making their estimation more difficult. Thanks to recent advances, it seems however possible to discriminate among oil and other stressors using reflectance spectroscopy (Emengini et al., 
2013b; Lassalle et al., 2019b, 2018). Because of the selective growing conditions imposed, only

390 few species are generally established on soils with oil (Noomen et al., 2012), as observed on our

391 study site. This makes the estimation of TPH feasible, provided that these species are oil-

392 sensitive. Species richness is however very high in some tropical regions subject to oil

393 contamination (Arellano et al., 2017a, 2017b). Such diversity in plant species means important

394 differences in sensitivity to oil among them. Some species are totally tolerant to oil, whereas

395 others are affected even at very low concentration. This makes the estimation of TPH more

396 difficult, so it is necessary to identify the most suitable species before, as we did under controlled 397 conditions.

398
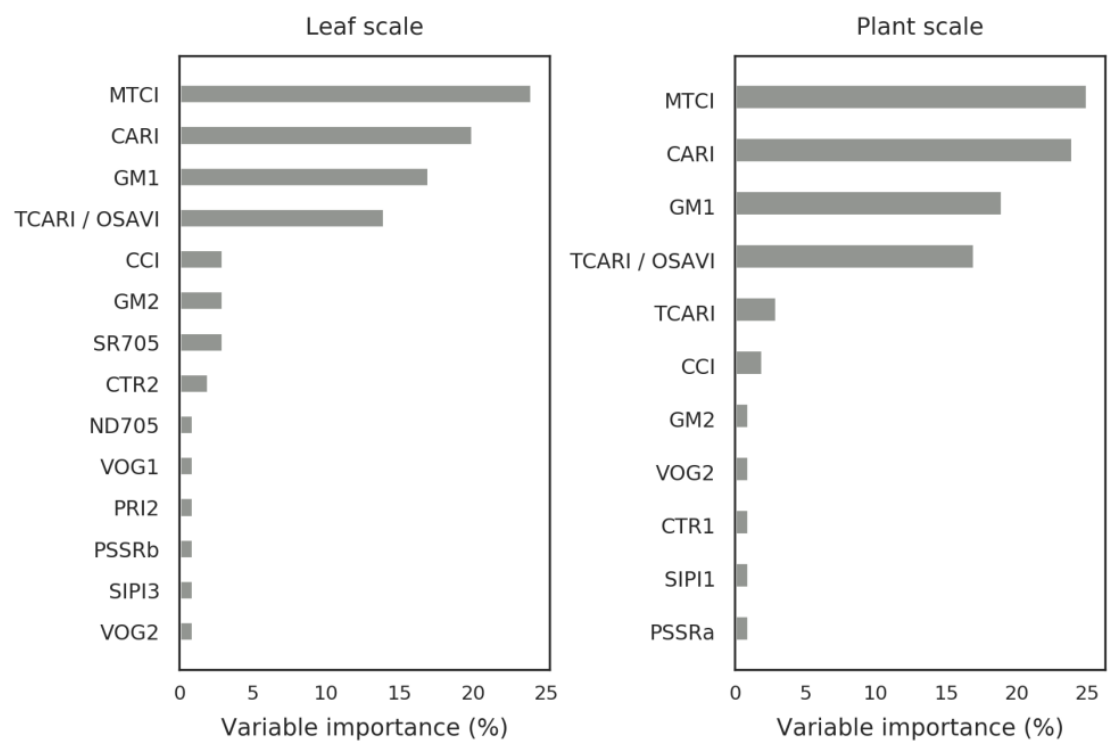

Figure 5. Relative contribution of the vegetation indices to the estimation of Total Petroleum

401 Hydrocarbons (TPH) using random forest regression, at leaf and plant scales. Only indices with non-zero contribution are displayed.

\section{Conclusion}

405 This study aimed to quantify low TPH concentrations in soils using C. alopecuroides 406 reflectance under controlled tropical conditions. Modifications in leaf biochemistry appeared 407 after a long-term exposure, depending on the level of contamination. Pigment contents were 408 reduced for TPH concentrations of $5 \mathrm{~g}^{\mathrm{kg}} \mathrm{kg}^{-1}$ and above, whereas they increased at lower 
409 concentration when compared to control. These modifications were linked to the reflectance data

410 through VI, which brought evidence of the implication of chlorophylls and various carotenoids in

411 the spectral response of the species to oil. The same indices succeeded in predicting TPH

412 concentrations with good accuracy using RF regressions, at leaf and plant scales. Four out of the

41333 indices tested were almost sufficient to achieve these predictions. This study emphasizes the

414 potential of reflectance spectroscopy for quantifying oil contamination in tropical regions with

415 dense vegetation. More specifically, the long-term response of C. alopecuroides to oil highlights

416 its interest for assessing persistent contamination, for example after cessation of the oil

417 production activity. Although our approach is at early stage and needs further improvements, we

418 are convinced that it could soon result in imagery applications. The emergence of new satellite-

419 and UAV-embedded hyperspectral sensors is sparking a growing interest by oil and gas

420 companies, because they could help assessing oil contamination locally or at large scale. Our

421 study under controlled conditions was the first necessary step prior to such applications. In its

422 continuity, our upcoming research will focus on the adaptation of the approach to hyperspectral

423 imagery with high spatial resolution, and its assessment in tropical region with heavy past oil and

424 gas production activities.

425

426 Acknowledgements

427 This interdisciplinary work was achieved in the frame of the NAOMI R\&D project between 428 TOTAL and the ONERA, with the support of Ecolab and Dynafor research units of Toulouse. 429 The authors gratefully acknowledge E. Buffan-Dubau, D. Lambrigot and O. Berseille for their 430 assistance in pigment analysis.

431 Declarations of interest: None.

432 Funding: Financial support of this work was provided by TOTAL. 
Achard, V., Fabre, S., Alakian, A., Dubucq, D., Déliot, P., 2018. Direct or indirect on-shore hydrocarbon detection methods applied to hyperspectral data in tropical area, in: Michel, U., Schulz, K. (Eds.), Earth Resources and Environmental Remote Sensing/GIS Applications IX. SPIE, p. 22. https://doi.org/10.1117/12.2325097

Adamu, B., Tansey, K., Ogutu, B., 2018. Remote sensing for detection and monitoring of vegetation affected by oil spills. Int. J. Remote Sens. 39, 3628-3645. https://doi.org/10.1080/01431161.2018.1448483

Adamu, B., Tansey, K., Ogutu, B., 2016. An investigation into the factors influencing the detectability of oil spills using spectral indices in an oil-polluted environment. Int. J. Remote Sens. 37, 2338-2357. https://doi.org/10.1080/01431161.2016.1176271

Ahmadun, F.-R., Pendashteh, A., Abdullah, L.C., Awang Biak, D.R., Madaeni, S.S., Abidin, Z.Z., 2009. Review of technologies for oil and gas produced water treatment. J. Hazard. Mater. 170, 530-551. https://doi.org/10.1016/j.jhazmat.2009.05.044

Arellano, P., Tansey, K., Balzter, H., Boyd, D.S., 2017a. Field spectroscopy and radiative transfer modelling to assess impacts of petroleum pollution on biophysical and biochemical parameters of the Amazon rainforest. Environ. Earth Sci. 76, 1-14. https://doi.org/10.1007/s12665-017-6536-6

Arellano, P., Tansey, K., Balzter, H., Boyd, D.S., 2015. Detecting the effects of hydrocarbon pollution in the Amazon forest using hyperspectral satellite images. Environ. Pollut. 205, 225-239. https://doi.org/10.1016/j.envpol.2015.05.041

Arellano, P., Tansey, K., Balzter, H., Tellkamp, M., 2017b. Plant family-specific impacts of petroleum pollution on biodiversity and leaf chlorophyll content in the Amazon rainforest of Ecuador. PLoS One 12. https://doi.org/10.1371/journal.pone.0169867

Asner, G.P., 1997. Biophysical and Biochemical Sources of Variability in Canopy Reflectance. Remote Sens. Environ. 64, 234-253.

Athar, H. ur R., Ambreen, S., Javed, M., Hina, M., Rasul, S., Zafar, Z.U., Manzoor, H., Ogbaga, C.C., Afzal, M., Al-Qurainy, F., Ashraf, M., 2016. Influence of sub-lethal crude oil concentration on growth, water relations and photosynthetic capacity of maize (Zea mays L.) plants. Environ. Sci. Pollut. Res. 23, 18320-18331. https://doi.org/10.1007/s11356-0166976-7

Balasubramaniyam, A., Harvey, P.J., 2014. Scanning electron microscopic investigations of root structural modifications arising from growth in crude oil-contaminated sand. Environ. Sci. Pollut. Res. 21, 12651-12661. https://doi.org/10.1007/s11356-014-3138-7

Balliana, A.G., Moura, B.B., Inckot, R.C., Bona, C., 2017. Development of Canavalia ensiformis in soil contaminated with diesel oil. Environ. Sci. Pollut. Res. 24, 979-986. https://doi.org/10.1007/s11356-016-7674-1 
Barlow, R.G., Cummings, D.G., Gibb, S.W., 1996. Improved resolution of mono- and divinyl chlorophylls $\mathrm{a}$ and $\mathrm{b}$ and zeaxanthin and lutein in phytoplankton extracts using reverse phase C-8 HPLC. Mar. Ecol. Prog. Ser. 161, 303-307.

Barraza, F., Maurice, L., Uzu, G., Becerra, S., López, F., Ochoa-Herrera, V., Ruales, J., Schreck, E., 2018. Distribution, contents and health risk assessment of metal(loid)s in small-scale farms in the Ecuadorian Amazon: An insight into impacts of oil activities. Sci. Total Environ. 622-623, 106-120. https://doi.org/10.1016/j.scitotenv.2017.11.246

Baruah, P., Saikia, R.R., Baruah, P.P., Deka, S., 2014. Effect of crude oil contamination on the chlorophyll content and morpho-anatomy of Cyperus brevifolius (Rottb.) Hassk. Environ. Sci. Pollut. Res. 21, 12530-12538. https://doi.org/10.1007/s11356-014-3195-y

Bejarano, A.C., Michel, J., 2016. Oil spills and their impacts on sand beach invertebrate communities: A literature review. Environ. Pollut. 218, 709-722. https://doi.org/10.1016/j.envpol.2016.07.065

Belsley, D.A., Kuh, E., Wemsch, R.E., 1980. Detecting and Assessing Collinearity, in: John Wiley \& Sons, I. (Ed.), Regression Diagnostics: Idenhfiing Injuential Data and Sources of Collineariq.

Blackburn, G.A., 1998. Quantifying chlorophylls and carotenoids at leaf and canopy scales: An evaluation of some hyperspectral approaches. Remote Sens. Environ. 66, 273-285. https://doi.org/10.1016/S0034-4257(98)00059-5

Breiman, L., 2001. Random forests. Mach. Learn. 45, 5-32. https://doi.org/https://doi.org/10.1023/A:1010933404324

Chang, J.I., Lin, C.C., 2006. A study of storage tank accidents. J. Loss Prev. Process Ind. 19, 5159. https://doi.org/10.1016/j.jlp.2005.05.015

Correa Pabón, R.E., de Souza Filho, C.R., 2016. Spectroscopic characterization of red latosols contaminated by petroleum-hydrocarbon and empirical model to estimate pollutant content and type. Remote Sens. Environ. 175, 323-336. https://doi.org/10.1016/j.rse.2016.01.005

Correa Pabón, R.E., de Souza Filho, C.R., Oliveira, W.J. de, 2019. Reflectance and imaging spectroscopy applied to detection of petroleum hydrocarbon pollution in bare soils. Sci. Total Environ. 649, 1224-1236. https://doi.org/10.1016/j.scitotenv.2018.08.231

Credoz, A., Hédacq, R., Barreau, C., Dubucq, D., 2016. Experimental study of hyperspectral responses of plants grown on mud pit soil, in: Earth Resources and Environmental Remote Sensing/GIS Applications VII. p. 100051E. https://doi.org/10.1117/12.2239606

Dash, J., Curran, P.J., 2007. Evaluation of the MERIS terrestrial chlorophyll index (MTCI). Adv. Sp. Res. 39, 100-104. https://doi.org/10.1016/j.asr.2006.02.034

Diepens, N.J., Buffan-Dubau, E., Budzinski, H., Kallerhoff, J., Merlina, G., Silvestre, J., Auby, I., Nathalie Tapie, Elger, A., 2017. Toxicity effects of an environmental realistic herbicide mixture on the seagrass Zostera noltei. Environ. Pollut. 222, 393-403. https://doi.org/10.1016/j.envpol.2016.12.021 
Dormann, C.F., Elith, J., Bacher, S., Buchmann, C., Carl, G., Carré, G., Marquéz, J.R.G., Gruber, B., Lafourcade, B., Leitão, P.J., Münkemüller, T., McClean, C., Osborne, P.E., Reineking, B., Schröder, B., Skidmore, A.K., Zurell, D., Lautenbach, S., 2013. Collinearity: a review of methods to deal with it and a simulation study evaluating their performance. Ecography (Cop.). 36, 27-46. https://doi.org/10.1111/j.1600-0587.2012.07348.x

Durango-Cordero, J., Saqalli, M., Laplanche, C., Locquet, M., Elger, A., 2018. Spatial Analysis of Accidental Oil Spills Using Heterogeneous Data: A Case Study from the North-Eastern Ecuadorian Amazon. Sustainability 10, 4719. https://doi.org/10.3390/su10124719

Emengini, E.J., Blackburn, G.A., Theobald, J.C., 2013a. Early detection of oil-induced stress in crops using spectral and thermal responses. J. Appl. Remote Sens. 7. https://doi.org/10.1117/1.jrs.7.073596

Emengini, E.J., Blackburn, G.A., Theobald, J.C., 2013b. Detection and discrimination of oil and water deficit-induced stress in maize (Zea mays L.) using spectral and thermal responses. IOSR J. Environ. Sci. Toxicol. Food Technol. 3, 53-57.

Emengini, E.J., Ezeh, F.C., Chigbu, N., 2013c. Comparative Analysis of Spectral Responses of Varied Plant Species to Oil Stress. Int. J. Sci. Eng. Res. 4, 1421-1427.

Feret, J.B., François, C., Asner, G.P., Gitelson, A.A., Martin, R.E., Bidel, L.P.R., Ustin, S.L., le Maire, G., Jacquemoud, S., 2008. PROSPECT-4 and 5: Advances in the leaf optical properties model separating photosynthetic pigments. Remote Sens. Environ. 112, 30303043. https://doi.org/10.1016/j.rse.2008.02.012

Finer, M., Jenkins, C.N., Pimm, S.L., Keane, B., Ross, C., 2008. Oil and gas projects in the Western Amazon: Threats to wilderness, biodiversity, and indigenous peoples. PLoS One 3. https://doi.org/10.1371/journal.pone.0002932

Grömping, U., 2009. Variable importance assessment in regression: Linear regression versus random forest. Am. Stat. 63, 308-319. https://doi.org/10.1198/tast.2009.08199

Gürtler, S., de Souza Filho, C.R., Sanches, I.D., Alves, M.N., Oliveira, W.J., 2018. Determination of changes in leaf and canopy spectra of plants grown in soils contaminated with petroleum hydrocarbons. ISPRS J. Photogramm. Remote Sens. 146, 272-288. https://doi.org/10.1016/j.isprsjprs.2018.09.011

Haboudane, D., Miller, J.R., Tremblay, N., Zarco-Tejada, P.J., Dextraze, L., 2002. Integrated narrow-band vegetation indices for prediction of crop chlorophyll content for application to precision agriculture. Remote Sens. Environ. 81, 416-426. https://doi.org/10.1016/S00344257(02)00018-4

Hastie, T., Tibshirani, R., Friedman, J., 2017. The Elements of Statistical Learning The Elements of Statistical Learning.

Hu, G., Li, J., Zeng, G., 2013. Recent development in the treatment of oily sludge from petroleum industry: A review. J. Hazard. Mater. 261, 470-490. https://doi.org/10.1016/j.jhazmat.2013.07.069 
Hutengs, C., Vohland, M., 2016. Downscaling land surface temperatures at regional scales with random forest regression. Remote Sens. Environ. 178, 127-141. https://doi.org/10.1016/j.rse.2016.03.006

Kirk, J.L., Klironomos, J.N., Lee, H., Trevors, J.T., 2002. Phytotoxicity assay to assess plant species for phytoremediation of petroleum-contaminated soil. Bioremediat. J. 6, 57-63. https://doi.org/10.1080/10889860290777477

Lassalle, G., Credoz, A., Fabre, S., Elger, A., Hédacq, R., Dubucq, D., 2017. Hyperspectral signature analysis of three plant species to long-term hydrocarbon and heavy metal exposure, in: Michel, U., Schulz, K. (Eds.), Earth Resources and Environmental Remote Sensing/GIS Applications VIII. SPIE, p. 33. https://doi.org/10.1117/12.2277709

Lassalle, G., Credoz, A., Hédacq, R., Fabre, S., Dubucq, D., Elger, A., 2018. Assessing Soil Contamination Due to Oil and Gas Production Using Vegetation Hyperspectral Reflectance. Environ. Sci. Technol. 52, 1756-1764. https://doi.org/10.1021/acs.est.7b04618

Lassalle, G., Fabre, S., Credoz, A., Hédacq, R., Bertoni, G., Dubucq, D., Elger, A., 2019a. Application of PROSPECT for estimating total petroleum hydrocarbons in contaminated soils from leaf optical properties. J. Hazard. Mater. 377, 409-417. https://doi.org/10.1016/j.jhazmat.2019.05.093

Lassalle, G., Fabre, S., Credoz, A., Hédacq, R., Borderies, P., Bertoni, G., Erudel, T., BuffanDubau, E., Dubucq, D., Elger, A., 2019b. Detection and discrimination of various oilcontaminated soils using vegetation reflectance. Sci. Total Environ. 655, 1113-1124. https://doi.org/10.1016/j.scitotenv.2018.11.314

Li, Y., Morris, J.T., Yoch, D.C., 1990. Chronic Low Level Hydrocarbon Amendments Stimulate Plant Growth and Microbial Activity in Salt-Marsh Microcosms. J. Appl. Ecol. 27, 159171. https://doi.org/10.2307/2403575

Lin, Q., Mendelssohn, I.A., Suidan, M.T., Lee, K., Venosa, A.D., 2002. The dose-response relationship between No. 2 fuel oil and the growth of the salt marsh grass, Spartina alterniflora. Mar. Pollut. Bull. 44, 897-902. https://doi.org/10.1016/S0025-326X(02)001182

Maliszewska-Kordybach, B., Smreczak, B., 2000. Ecotoxicological Activity of Soils Polluted with Polycyclic Aromatic Hydrocarbons (PAHs) - Effect on Plants. Environ. Technol. 21, 1099-1110. https://doi.org/10.1080/09593330.2000.9618996

Merk1, N., Schultze-Kraft, R., Infante, C., 2004. Phytoremediation in the tropics-the effect of crude oil on the growth of tropical plants. Bioremediat. J. 8, 177-184. https://doi.org/10.1080/10889860490887527

Milton, E.J., 1987. Principles of field spectroscopy. Int. J. Remote Sens. 8, 1807-1827. https://doi.org/https://doi.org/10.1080/01431168708954818

Mutanga, O., Adam, E., Cho, M.A., 2012. High density biomass estimation for wetland vegetation using worldview-2 imagery and random forest regression algorithm. Int. J. Appl. 
Earth Obs. Geoinf. 18, 399-406. https://doi.org/10.1016/j.jag.2012.03.012

586

587

588

Nie, M., Lu, M., Yang, Q., Zhang, X., Xiao, M., Jiang, L., Yang, J., Fang, C., Chen, J., Li, B., 2011. Plants ' use of different nitrogen forms in response to crude oil contamination 159, 157-163. https://doi.org/10.1016/j.envpol.2010.09.013

Noomen, M.F., van der Werff, H.M.A., van der Meer, F.D., 2012. Spectral and spatial indicators of botanical changes caused by long-term hydrocarbon seepage. Ecol. Inform. 8, 55-64. https://doi.org/10.1016/j.ecoinf.2012.01.001

Ogri, O.R., 2001. A review of the Nigerian petroleum industry and the associated environmental problems. Environmentalist 21, 11-21. https://doi.org/https://doi.org/10.1023/A:1010633903226

Romero, I.C., Toro-Farmer, G., Diercks, A.R., Schwing, P., Muller-Karger, F., Murawski, S., Hollander, D.J., 2017. Large-scale deposition of weathered oil in the Gulf of Mexico following a deep-water oil spill. Environ. Pollut. 228, 179-189. https://doi.org/10.1016/j.envpol.2017.05.019

Rosso, P.H., Pushnik, J.C., Lay, M., Ustin, S.L., 2005. Reflectance properties and physiological responses of Salicornia virginica to heavy metal and petroleum contamination. Environ. Pollut. 137, 241-252. https://doi.org/10.1016/j.envpol.2005.02.025

Salanitro, J.P., Dorn, P.B., Huesemann, M.H., Moore, K.O., Rhodes, I.A., Rice Jackson, L.M., Vipond, T.E., Western, M.M., Wisniewski, H.L., 1997. Crude oil hydrocarbon bioromediation and soil ecotoxicity assessment. Environ. Sci. Technol. 31, 1769-1776. https://doi.org/10.1021/es960793i

Sanches, I.D., de Souza Filho, C.R., Magalhães, L.A., Quitério, G.C.M., Alves, M.N., Oliveira, W.J., 2013a. Assessing the impact of hydrocarbon leakages on vegetation using reflectance spectroscopy. ISPRS J. Photogramm. Remote Sens. 78, 85-101. https://doi.org/10.1016/j.isprsjprs.2013.01.007

Sanches, I.D., Souza Filho, C.R., Magalhães, L.A., Quitério, G.C.M., Alves, M.N., Oliveira, W.J., 2013b. Unravelling remote sensing signatures of plants contaminated with gasoline and diesel: An approach using the red edge spectral feature. Environ. Pollut. 174, 16-27. https://doi.org/10.1016/j.envpol.2012.10.029

Savitzky, A., Golay, M.J.E., 1964. Smoothing and Differentiation of Data by Simplified Least Squares Procedures. Anal. Chem. 36, 1627-1639. https://doi.org/10.1021/ac60214a047

Scafutto, R.D.M., de Souza Filho, C.R., 2016. Quantitative characterization of crude oils and fuels in mineral substrates using reflectance spectroscopy: Implications for remote sensing. Int. J. Appl. Earth Obs. Geoinf. 50, 221-242. https://doi.org/10.1016/j.jag.2016.03.017

Scafutto, R.D.P.M., de Souza Filho, C.R., de Oliveira, W.J., 2017. Hyperspectral remote sensing detection of petroleum hydrocarbons in mixtures with mineral substrates: Implications for onshore exploration and monitoring. ISPRS J. Photogramm. Remote Sens. 128, 146-157. https://doi.org/10.1016/j.isprsjprs.2017.03.009 
623

624
Shi, T., Chen, Y., Liu, Y., Wu, G., 2014a. Visible and near-infrared reflectance spectroscopy An alternative for monitoring soil contamination by heavy metals. J. Hazard. Mater. 265, 166-176. https://doi.org/10.1016/j.jhazmat.2013.11.059

Shi, T., Liu, H., Wang, J., Chen, Y., Fei, T., Wu, G., 2014b. Monitoring arsenic contamination in agricultural soils with reflectance spectroscopy of rice plants. Environ. Sci. Technol. 48, 6264-6272. https://doi.org/10.1021/es405361n

Smith, K.L.L., Steven, M.D.D., Colls, J.J.J., 2004. Use of hyperspectral derivative ratios in the red-edge region to identify plant stress responses to gas leaks. Remote Sens. Environ. 92, 207-217. https://doi.org/10.1016/j.rse.2004.06.002

Tran, T.H., Gati, E.M., Eshel, A., Winter, G., 2018. Germination , physiological and biochemical responses of acacia seedlings ( Acacia raddiana and Acacia tortilis ) to petroleum contaminated soils *. Environ. Pollut. 234, 642-655. https://doi.org/10.1016/j.envpol.2017.11.067

Zhang, Y., Huang, J., Wang, F., Blackburn, G.A., Zhang, H.K., Wang, X., Wei, Chuanwen, Zhang, K., Wei, Chen, 2017. An extended PROSPECT: Advance in the leaf optical properties model separating total chlorophylls into chlorophyll a and b. Sci. Rep. 7. https://doi.org/10.1038/s41598-017-06694-y

Zou, H., Hastie, T., 2005. Regression and variable selection via the elastic net. J. R. Stat. Soc. Ser. B (Statistical Methodol. 67, 301-320. https://doi.org/10.1111/j.14679868.2005.00503.x 